\title{
The Comparative Study of Chinese-Japanese Temple Garden Stones Zhou Peng ${ }^{1}$ \\ ${ }^{1}$ Nanjing Forestry University, College of Landscape Architecture, Nanjing, 210037
}

hunter2011@foxmail.com

Keywords: Stone; Temple Garden; Art

\begin{abstract}
Stone" is a very important gardening element for the temple gardens, even to be the point that "no stone no garden", rockery stone home is the basic approach of the temple garden stone scene to create, and plays a very important role in our traditional gardening art in status. Learn from the achievements of the temple garden, Japanese temple garden evolves mainly for the same formations, landscape architecture Japanese temple gardens. Although imported from China, it lays the foundation for Japanese garden landscape as architecture. This paper uses literature and comparative analysis method, studies the similarities and differences between the two countries in art of stone temple garden practices, mood style, aesthetic and other aspects.
\end{abstract}

\section{Introduction}

Now for the link between the classical and the modern art of stone formations garden, art study is relatively small, there is no summed up for the "traditional" inherited methods, or that we are exploring how to inherit the essence of classical art of stone garden. From a comparative perspective, it can be found: the Japanese art of stone garden will respect at every stage in the transformation of traditional, inherit the essence of traditional culture, and bold innovation, so as to form both the sense of the times, but also the expression of the national spirit connotation of traditional formations artistic landscape. Between Chinese and Japanese Classical Gardens belong to the Oriental garden system, both the same root. In the long-term cultural exchanges, Chinese art is heavily influenced by Japanese classical garden temple gardens. Its landscape skeleton came there from China, and to develop a prototype of a Japanese-style garden in the spring pool. And after the Heian period, the two countries were developing their different styles, the practice formed a new style of the Ming and Qing China before a change, while Japan is working on ways and means of classical heritage, and ultimately formed a Japanese traditional folk the unique landscape rocks spirit.

In ancient times, the temple gardens in particular private gardens, but closed due to the limited area enclosed, artificial reproduction of natural mountain which occupies a very prominent position. The use of natural materials, the use of technology and art practices, local conditions, rockery stone home, and create a beautiful formation, the performance of the steep mountains and deep natural, man-made creation of a "second nature." Times are different now, Chinese modern art of stone garden at promoting the reform and opening up and economic development, has undergone great changes, not only out of the tradition of the detention, and concern of the international style, especially in recent years, a considerable number of outstanding garden stone scene works published. But in the development process, there have been many problems: Some garden stone scene bold reform and development works gradually lost its national identity, in line with the times, although in the form of features, functions to meet the needs, but with the traditional culture interruption. Regardless of the occasion, heap mountains Stones rampant, whether it is empty squares, parks, or residential area, everywhere in the heap false, big and empty rockery, neither the traditional culture, but did not play the effect of beautifying the environment, even Some formations designed body is too large, the proportion is quite inconsistent with the environment, resulting in congestion on aesthetic, resulting in visual fatigue. In short, our modern garden in the style of stone scene chaos, is still in the exploratory stage. As a design workers, we have a responsibility to investigate how the tradition of Chinese classical garden design elements-"stone" cut into the 
modern landscape designs, as well as how to learn from the Japanese art of stone heritage park classical ways and means, inheriting the essence of traditional stone-scenery design and on the basis of our garden, combined with modern design techniques and design theory, innovation and the development of Chinese classical garden art of stone, and on this basis to explore the development of modern art formations of the future.

\section{The Comparison of Chinese-Japanese Art of Stone Garden Historical Origins}

Japan, the Japanese art of stone with Chinese classical garden as in Asuka, Nara period, China's Buddhism, immortal thought passed, but also to simulate the mountains start. Ancient Chinese myths and legends of Penglai, a symbol of immortality animals - turtle and the crane, then evolved into a Japanese garden in Penglai ancient rock group rock group crane and tortoise. Asuka period, after the introduction of Buddhism to Japan, the Japanese quickly accepted. In order to express their Buddha, God of admiration, the Buddhism, immortal thought directly as gardening theme and mood. Led directly to the emergence of three Japanese classical garden stone group, Sumeru rocks group. Japan created the first model of ancient stone garden group.

Song in the World Zen ink painting and brought to Japan, the Japanese and their absorption with their own native culture, to create a rich strong national characteristics dry landscape. Rocks and sand bar given more symbolic meaning. After that, in thinking, further affecting Zen Chinese tea culture, the evolution of the Japanese tea court, open field. "Open field" flying stone, squat and so let Zen penetrate into specific behavioral activity, allowing both practical functions with stone landscaping function, mood and techniques are reaching full maturity, has been a qualitative leap.

The case of Japan Gardens continues its iconic stone temple garden and learns art of stone, Buddhism, immortal thoughts, Zen tea culture, the traditional culture and national character of its artistic formations still legible. Through imitation, integration of Chinese culture and innovation will be the art of stone garden complex nature of evolution, the Japanese art of stone not only classical garden art of stone temples assimilation or simple copy, but showing a wide range, compatible, inheritance but innovation for the Japanese classical garden art of stone written a glorious history.

\section{The Comparison of Chinese-Japanese Temple Garden Stone Scene}

Japanese temple garden in the beginning of the way to create a stone scene is the same, all located in the rockery stone home, mimicking the natural landscape. But developed later, a qualitative change in the two formations Temple Garden Art has occurred. Shi in the ancient Japanese garden is the developed and influenced by traditional Chinese culture. Ancient Japanese garden formations create initially inherited and learn Chinese Wei skeleton landscape natural landscape garden, to the Heian period, the Japanese began to combine their local culture and learn from Zen Buddhist ideas, developed with strong ethnic characteristics of the Japanese dry landscape. The art of stone temple garden in the skeleton on the basis of the natural landscape, learning the Song Dynasty ink mood, develop an abstract impressionistic landscape formations. Following on the Japanese temple garden stone scene created by comparing the difference in detail.

Two temple garden stone scene to create differences mainly in the following aspects:

1, in the selection, the temple garden stone scene selected stone with "transparent, thin, leak, wrinkle," for the United States, like to use Taihu, Japan's ancient garden stone scene selected stone to vigorous, stocky, athletic person for you, happy with Mikage stone, bluestone, stone pommel horse.

2, set the stone in the direction and volume, set stone temple gardens more vertical stacking, multi-tall stone body; Japanese temple garden stones set multi lateral level is set, more low stone body.

3. Type in the formations, ancient Japanese garden stone scene is continental, mountain type; Japan's ancient garden stone - scenery, mostly island type, water type. 
4, in the formations to create a gimmick, Chinese ancient stone scene to create a multi-use park Stones be mountains or in combination with other elements of the garden practices; ancient Japanese garden stone scene create a multi-use building mountains spring method, set stone method (interspersed), dry landscape gardens or in combination with other elements.

5. On the mood style temple garden mood pursuit of natural stone scene real, poetic and Taoism in "Heaven" philosophy; Japanese temple garden beyond the pursuit of natural artificial stone scenery mood, "the bad thing" as well as the significance of Zen Buddhism.

\section{The Comparison on Aesthetic of Chinese-Japanese Temple Garden Stone}

"Tuo beauty" refers to the tea ceremony detached human accident, the pursuit of aesthetic realm quiet and Happy. Hermitage Chamber formations with tea Momoyama era represented. It absorbed the Zen aesthetic approach and mood, but the focus and dry landscape is different. Dry landscape performance is quiet, Kuji United States, Hermitage tea tribunal nude step stone symbol of rugged mountain stone paths to ground pine needles hint lush forests to crouching wash bowl symbol of holy spring water, with temples and shrines walls, stone lantern imitation temple shrine solemn quiet, Shi Zen aesthetic nature is manifested in nature. These are all in pursuit of the aesthetic realm of quiet and pay attention to the tea ceremony are Happy - Tacitus.

Geographical differences in Japanese environmental and cultural aspects of thinking lead the different formations artistic aesthetic. Aesthetic includes aesthetic subject, aesthetic object and aesthetic intermediary. Following on from the three aspects of the Japanese temple garden art of stone aesthetic differences were compared.

First, the aesthetic subject, the Japanese art of stone temple garden to create a body are Asians, are influenced by Eastern culture. However, due to differences in the two geographical environment, history and length, it shows their different artistic aesthetic. Chinese Shi artistic aesthetic subject mainly writers, they live on the mainland, as partners in the mountains, has a long history, so they tend to aesthetic artistic formations to overcome the natural optimism after. The main body of the Japanese temple garden aesthetic art of stone is swordsman and monks, who live on the island, and ocean as partners, natural disasters, and short history. That is why the artistic aesthetic formations tend to grievances in natural disaster under the pessimistic attitude.

Second, from the point of view aesthetic object, Temple Gardens Shijingshan ones and mostly tall, stone too few (mainly marble types); while Japanese temple gardens too few of Shijingshan and low, gravel ones.

Third, in the aesthetic mediation, China is affected by Confucianism, the main use of pure, artistic means conduct temple garden art of stone aesthetic activity, and therefore to pursue artistic formations natural beauty, beauty of form and Mood. Japan is influenced by Zen Buddhism, the main activity is carried out with the idea of aesthetic formations religion, so the pursuit of "sad, lonely beauty" and "Tuo beauty" formations Art. Ultimate aesthetic point of view, the aesthetic art of stone temple garden is the ultimate Heaven, and the aesthetic of the ancient Japanese art of stone garden Buddha ultimate human unity.

\section{Conclusion}

Chinese and Japanese temple gardens belong to the natural landscape garden, the same landscape as the backbone of the landscape, Chikuyama marble also becomes the focus of their garden art. Temple Gardens is known as no stone no garden, the stone and water garden composed become the indispensable elements. "Chang Wu Chi" goes: "It is the ancient stone, water very far away, garden stone water, most can not do without it." Marble correspondingly become one of the most important elements of gardening. "The mountains hung stone water because Shiqing," "no room stone indecent, stone garden does not show." For thousands of years, it creates a landscape of stones become artistic core. Rockery stone home garden landscaping is not only functional, but cultivate people's sentiments, and gives spiritual enjoyment. 


\section{References}

[1] T. Jin, Y.S. Yang. The Role Of Rockery Stone and Set in A Landscape. Hunan Forestry, 2007 (3): 10.

[2] Y.Y. Xing. Japanese Garden Culture of the Heian Period. EXPLORATION, 2011 (11).

[3] Z. Zhai. Inner Garden-Historical Dry Landscape Formation. Shanghai: Shanghai Commercial, 2010 (9).

[4] X.F. Chen. S.W. Lin. China Zen Influence on Japanese Garden Style. Chinese Journal Of Buddhist Studies, 2002 (6): 465.

[5] Y.M. Hu. Anhui Garden Stone Study. Chinese Garden, 1998.14 (6): 37-40. 